\title{
PENERAPAN PEMBELAJARAN JARAK JAUH UNTUK MENINGKATKAN \\ PEMAHAMAN KONSEP MATEMATIS SISWA SMP-IT ALAMY SUBANG
}

\author{
Euis Anih \\ STKIP Subang \\ euisanih@yahoo.co.id
}

\begin{abstract}
This research is about learning mathematics by distance learning which is intended as an effort to improve the ability to understand concepts in mathematics learning. The purpose of this study was to determine the increase in the conceptual understanding of students who received mathematics learning by distance learning, and to determine students' attitudes towards learning mathematics by distance learning. The research method used was Expo Facto research. The independent variable in this study is distance learning and the dependent variable is the students' ability to understand mathematical concepts. The research subjects were students of SMP-IT Alamy Subang. The instruments used in this study were test and nontest instruments. The test instrument for students' ability to understand mathematical concepts is in the form of descriptions and non-tests in the form of an attitude scale questionnaire. The data analysis technique used is quantitative data and qualitative data using SPSS 20 for Windows and Microsoft Excel software. By using inferential statistics with a significance level of $5 \%$ shows an increase in students' ability to understand mathematical concepts by distance learning. To see students' attitudes towards distance learning, a Likert scale is used. The results of qualitative data concluded that almost all students gave negative responses to learning mathematics by distance learning.
\end{abstract}

Keywords: Distance Learning, Students Mathematical Concept Understanding Ability

\section{ABSTRAK}

Penelitian ini tentang pembelajaran matematika dengan pembelajaran jarak jauh yang dimaksudkan sebagai salah satu upaya untuk meningkatkan kemampuan pemahaman konsep dalam pembelajaran matematika. Tujuan penelitian ini adalah untuk mengetahui peningkatan kemampuan pemahaman konsep siswa yang memperoleh pembelajaran matematika dengan pembelajaran jarak jauh, serta untuk mengetahui sikap siswa terhadap pembelajaran matematika dengan pembelajaran jarak jauh. Metode penelitian yang digunakan adalah penelitian Expo Facto. Yang menjadi variabel bebas dalam penelitian ini adalah pembelajaran jarak jauh dan variabel terikatnya kemampuan pemahaman konsep matematis siswa. Subjek penelitiannya adalas Siswa SMP-IT Alamy Subang. Instrumen yang digunakan dalam penelitian ini adalah instrumen tes dan non tes. Instrument tes kemampuan pemahaman konsep matematis siswa berupa uraian dan non tes berupa angket skala sikap. Teknis analisis data yang digunakan adalah data kuantitatif dan data kualitatif menggunakan software SPSS 20 for Windows dan Microsoft excel. Dengan menggunakan statistic inferensial dengan taraf signifikansi 
$5 \%$ menunjukkan peningkatan kemampuan pemahaman konsep matematis siswa dengan pembelajaran jarak jauh. Untuk melihat sikap siswa terhadap pembelajaran jarak jauh digunakan skala likert. Hasil data kualitatif diperoleh kesimpulan bahwa hampir seluruhnya siswa memberikan respon negatif terhadap pembelajaran matematika dengan pembelajaran jarak jauh.

Kata kunci : Pembelajaran Jarak Jauh, Kemampuan Pemahaman Konsep Matematis Siswa

\section{A. Pendahuluan}

Matematika merupakan mata pelajaran yang sangat penting dalam dunia pendidikan fomal dari SD hingga SMA bahkan perguruan tinggi mata pelajaran matematika selalu ada. Matematika adalah ilmu pasti, matematika juga merupakan salah satu ilmu yang paling sering digunakan dalam kehidupan seharihari. Menurut Surya dan Sari (2017:11) matematika adalah salah satu cabang ilmu pengetahuan yang paling penting. Selain itu, matematika juga sangat penting bagi siswa untuk belajar dan memahami mata pelajaran lain, namun nyatanya banyak siswa kurang menarik dengan pembelajaran matematika.

Mengingat pentingnya peran matematika dalam berbagai bidang kehidupan, maka upaya untuk meningkatkan pendidikan matematika harus terus dilakukan. Dalam kurikulum 2013 Lampiran 3 Permendikbud No. 28 (Kemendikbud, 2014, hlm. 325) tujuan yang ingin dicapai melalui pembelajaran matematika adalah : (1) Memahami konsep matematika, merupakan kompetensi dalam menjelaskan keterkaitan antar konsep dan menggunakan konsep maupun algoritma, secara luwes, akurat, efesien dan tepat dalam pemecahan masalah, (2) Menggunakan pola sebagai dugaan dalam penyelesaian masalah, dan mampu membuat generalisasi berdasarkan fenomena atau data yang ada, (3) Menggunakan penalaran pada sifat, melakukan manipulasi pada matematika baik dalam penyederhanaan, maupun menganalisa komponen yang ada dalam pemecahan masalah dalam konteks matematika maupun diluar matematika (kehidupan nyata, ilmu dan teknologi),

Mengkomunikasikan gagasan, penalaran, serta mampu menyusun bukti matematika dengan menggunakan kalimat lengkap, symbol, table, diagram, atau media lain untuk memperjelas keadaan atau 
masalah, (5) Memiliki sikap menghargai kegunaan matematika dalam kehidupan yaitu memiliki rasa ingin tahu, perhatian dan minat dalam mempelajari matematika, serta sikap ulet dan percaya diri dalam memecahkan masalah, (6) Memiliki sikap dan perilaku yang sesuai dengan nilai-nilai dalam matematika dan pembelajarannya, seperti taat azas, konsisten, menjungjung tinggi kesepakatan, toleran, menghargai pendapat orang lain, santun, demokrasi, ulet, tangguh, kreatif, menghargai kesemestaan (konteks, lingkungan), kerjasama, adil, jujur, teliti, cermat, bersikap luwes dan terbuk, memiliki kemauman berbagi rasa dengan orang lain,

Menggunakan alat peraga sederhana maupun hasil teknologi untuk melakukan kegiatan-kegiatan matematika. Berdasarkan tujuan yang ingin dicapai dalam pembelajaran matematika, kemampuan memahami konsep merupakan salah satu tujuan yang harus dicapai dan harus dikuasai oleh siswa.

Kemampuan pemahaman konsep matematis adalah salah satu tujuan penting dalam pembelajaran, karena dengan memahami konsep matematis siswa tidak hanya sekedar menghafal rumus tapi memahami konsep sebuah materi yang dipelajari dalam pembelajaran matematika. Namun kenyataan dilapangan ternyata kemampuan pemahaman konsep matematika masih rendah, hal ini dibuktikan dengan banyaknta siswa yang kurang memahami ketika materi sudah dihubungkan dengan aplikasi rumus dan angka.

Pada masa pandemi yang terjadi di Indonesia sekarang ini, pembelajaran jarak jauh merupakan sebuah alternatif untuk tetap melangsungkan pembelajaran. Karena pemerintah belum membolehkan pihak sekolah untuk para siswa nya kembali belajar disekolah seperti biasanya. Hanya saja beberapa sekolah yang wilayahnyanya sudah memasuki zona hijau diperbolehkan untuk melaksanakan pembelajaran secara langsung tetapi dengan protokol kesehatan yang telah ditentukan. Pembelajaran jarak jauh merupakan kegiatan belajar yang dilakukan siswa dirumah masing-masing tidak berkumpul disuatu kelas untuk menerima suatu pelajaran yang disampaikan oleh guru secara online atau daring. Dengan kata lain penerapan pembelajaran jarak jauh di 
masa pandemi sangat dianjurkan untuk dilakukan agar kegiatan belajar mengajar tetap bisa berlangsung.

Pembelajaran jarak jauh bisa menggunakan zoom meeting, telegram, google classroom, apowersoft, dan yang lainnya untuk meningkatkan aktivitas belajar siswa dirumah agar siswa tidak mudah bosan dengan pembelajaran jarak jauh ini. Pembelajaran jarak jauh bisa mendorong siswa untuk tetap belajar dalam menghadapi situasi yang darurat akibat pandemi covid-19. Penerapan pembelajaran jarak jauh diharapkan bisa menjadi alternatif untuk meningkatkan pemahaman konsep matematis siswa SMP-IT Alamy Subang.

Berdasarkan latar belakang yang telah diuraikan, penulis merasa perlu melakukan penelitian mengenai : "Penerapan Pembelajaran Jarak Jauh Untuk Meningkatkan Pemahaman Konsep Matematis Siswa SMP-IT Alamy Subang" Untuk mengetahui lebih jauh tentang pembelajaran jarak jauh terhadap pemahaman matematis siswa, maka perlu diteliti hal-hal berikut : (1) Bagaimana peningkatan kemampuan pemahaman konsep matematis siswa dengan cara sistem pembelajaran jarak jauh? (2) Bagaimana sikap siswa terhadap pembelajaran matematika dengan sistem pembelaran jarak jauh?

\section{B. Metode Penelitian}

Metode yang digunakan dalam penelitian ini adalah penelitian ekspos fakto (expost facto research) meneliti hubungan sebab-akibat yang tidak dimanipulasi atau diberikan perlakukan didalam penelitiannya oleh peneliti. Penelitian hubungan sebabakibat dilakukan terhadap program, kegiatan atau kejadian yang telah terjadi sebelumnya. Penelitian ini mirip dengan penelitian eksperimental tetapi tidak ada pengontrolan variabel.

Dalam penelitian ex post facto, data dikumpulkan setelah segala peristiwa terjadi, sehingga dalam pelaksanaannya tidak ada intervensi dari peneliti. Metode ini dipilih karena Indonesia sedang dilanda pandemi Covid-19 yang tidak memungkinkan peneliti untuk melakukan penelitian kuasi eksperimen. Penelitian ini bertujuan untuk mengetahui peningkatan pemahaman konsep matematis siswa dengan sistem pembelajaran jarak jauh yang telah diterapkan di SMP-IT Alamy Subang. 
Instrumen yang digunakan dalam penelitian ini adalah instrument data kuantitatif dan data kualitatif. Instrumen data kuantitatif berupa tes kemampuan pemahaman konsep matematis siswa yaitu pretest dan posttest sedangkan instrument data kualitatif yaitu non tes berupa angket. Angket yang digunakan dalam penelitian ini berupa kumpulan pertanyaan-pertanyaan tertulis untuk memperoleh informasi dari respon siswa. Angket yang digunakan yaitu angket skala sikap, tujuannya untuk mengetahui bagaimana sikap siswa terhadap pembelajaran matematika.

\section{Hasil Penelitian dan Pembahasan}

Berdasarkan beberapa tes yang dilakukan dalam penelitian ini, diperolah data sebagai berikut :

Tabel 1 Rekaptulasi Tes Kemampuan Pemahaman Konsep Matematis Siswa

\begin{tabular}{ccc}
\hline & Pretest & Posttest \\
\hline Jumlah Sampel & 34 & 34 \\
Skor Minimum & 0 & 10 \\
Skor Maximum & 28 & 28 \\
Mean & 17,56 & 22,15 \\
Standar Deviasi & 4,52 & 4,54 \\
Varians & 41,951 & 20,875 \\
\hline
\end{tabular}

Berdasarkan tabel 1 dapat dilihat bahwa skor tes kemampuan pemahaman konsep mengalami perubahan yang positif. Hal ini dapat dilihat dari rata-rata yaitu 17,56 menjadi 22,15. Berikut ini disajikan grafik hasil analisis deskriptif pada pretest dan posttest dengan menggunakan Microsoft Excel for windows.

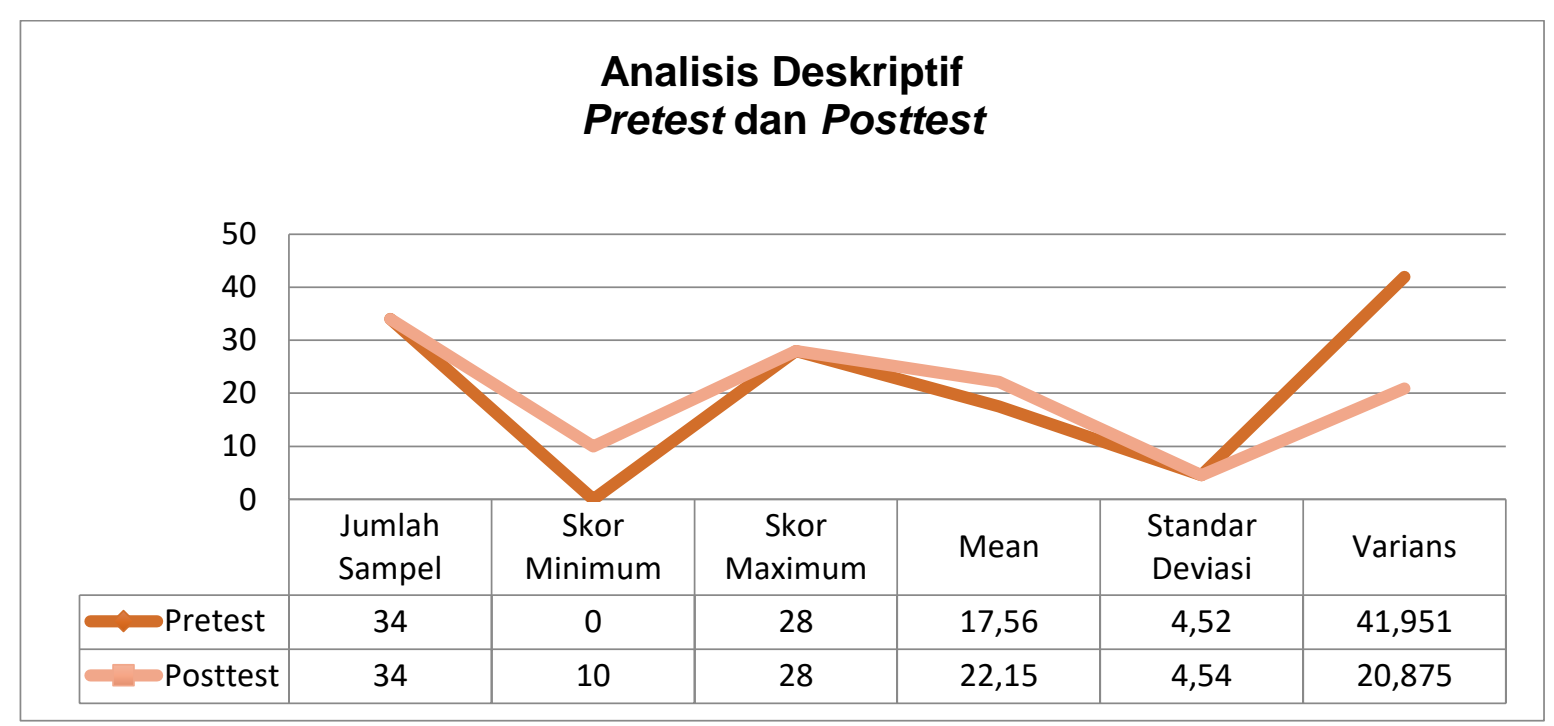

Gambar 1 Analisis Deskriptif Pretest dan Posttest 
Dari hasil deskripsi tes kemampuan pemahaman konsep matematis siswa di atas, maka kemampuan pemahaman konsep matematis siswa mengalami perubahan dengan pembelajaran jarak jauh. Dengan kata lain perubahan tersebut menunjukkan adanya peningkatan kemampuan pemahaman konsep matematis siswa. Peningkatan yang terjadi setelah pembelajaran jarak jauh, selanjutnya mencari $N$-Gain.

Tabel 2 N-Gain Tes Kemampuan Pemahaman Konsep Matematis Siswa

\begin{tabular}{cc}
\hline & $\mathbf{N}$-Gain \\
\hline Min & $-0,50$ \\
Max & 1 \\
Mean & 0,33 \\
Varians & 0,132 \\
Std.Deviasi & 0,36 \\
\hline
\end{tabular}

Pada tabel 2 menunjukkan bahwa rata-rata gain ternomalisasi kemampuan pemahaman konsep matematis siswa sebesar 0,33. Berdasarkan kategori gain ternomalisasi berada pada kriteria sedang. Artinya secara klasikal kemampuan pemahaman konsep matematis siswa dengan pembelajaran jarak jauh mengalami peningkatan yang sedang. Berikut ini disajikan grafik hasil analisis deskriptif pada $n$-gain dengan menggunakan Microsoft Excel for windows.

Berdasarkan perhitungan angket skala sikap yang terdiri dari 12 pertanyaan diperoleh 2,96 hal ini berarti siswa menunjukan respon negatif terhadap pembelajaran tersebut. Hal ini dikarenakan karena :
(1) Pembelajaran matematika dengan sistem pembelajaran jarak jauh sangat membingungkan siswa ketika ada materi yang sulit dipahami kalau mau konsultasi keguru susah, kendalanya biasanya matematika itu perlu penjelasan langsung kalaupun mau kesekolah pasti waktunya terbatas, (2) Kendala sinyal yang kadang tidak mendukung dan siswa yang tidak mempunyai alat komunikasi (handphone), (3) siswa lebih senang dengan pembelajaran tatap muka disekolah dibandingkan dengan pembelajaran jarak jauh karena bertemu dengan temantemannya yang membuat siswa semangat belajar, (4) menurut persepsi siswa pembelajaran jarak 
jauh tidak menyenangkan karena dibebankan tugas berlebih.

Dengan demikian pembelajaran jarak jauh merupakan salah satu upaya dalam pembelajaran di masa pandemic Covid 19 ini dirasa banyak mengandung kendala, tangtangan dan hambatannya. Hal ini dapat dijadikan dasar pertimbangan dalam mengambil keputusan dan solusi untuk pelaksanaan pembelajaran selanjutnya.

\section{Kesimpulan}

Berdasarkan hasil penelitian, diperoleh kesimpulan dengan pembelajaran matematika menggunakan sistem pembelajaran jarak jauh dalam meningkatkan kemampuan pemahaman konsep matematis siswa SMP-IT Alamy Subang, diperoleh beberapa kesimpulan yaitu: (1) Kemampuan pemahaman konsep matematis siswa SMP-IT Alamy Subang meningkat dalam kriteria sedang dengan sistem pembelajaran jarak jauh. (2) Sikap siswa menunjukan respon negatif terhadap pembelajaran matematika dengan sistem pembelajaran jarak jauh.

\section{DAFTAR PUSTAKA}

Afrilianto, M. (2012). Peningkatan Pemahaman Konsep Dan Kompetensi Strategis Matematis Siswa Smp Dengan Pendekatan Metaphorical Thinking. Infinity Journal, $\quad 192$. https://doi.org/10.22460/infinity.v $\underline{1 \mathrm{i} 2.19}$

Faizah, S. N. (2020). Hakikat Belajar Dan Pembelajaran. At-Thullab: Jurnal Pendidikan Guru Madrasah Ibtidaiyah, 1(2), 175. https://doi.org/10.30736/atl.v1i2. $\underline{85}$

Khalistin, \& Hidayanto. (2013). Penerapan Pendekatan Pembelajaran Open Ended untuk Meningkatkan Pemahaman Siswa Kelas VII-A SMP Negeri 1 Batu pada Materi Segi Empat. JurnalOnline.Um.Ac.Id, 1(1), 1-11.

Munir. (2009). Pembelajaran Jarak Jauh berbasis Teknologi Informasi dan Komunikasi (TIK). Bandung:Alfabeta, CV.

Riduwan., Adun Rusyana., \& Enas. (2011). Cara Mudah Belajar SPSS 17.0 dan Aplikasi Statistik Penelitian. Bandung:Alfabeta.

Ruseffendi, (2005). Dasar-Dasar

Penelitian \& Bidang Non- 
Eksakta Lainnya.

Bandung:TARSITO.

Siagian, M. D. (2017). Pembelajaran

Matematika Dalam Persfektif

Konstruktivisme. NIZHAMIYAH:

Jurnal Pendidikan Islam Dan

Teknologi Pendidikan, VII(2),

61-73.

Sugiono, (2012). Statistik

Nonparametris untuk Penelitian.

Bandung:CV.Alfabeta.

Sugiyono, (2016). Metode Penelitian

Kuantitatif, Kualitatif, Dan $R \& D$.

Bandung:ALFABETA.

Syaodih Sukmadinata, Nana. (2017).

Metode Penelitian

Pendidikan.Bandung:PT Remaja

Rosdakarya Offset.

Sri Apriyani, Dede (2016). Penerapan

Model Pembelajaran Problem

Based Learning untuk

Meningkatkan Kemampuan

Pemahaman Konsep Matematis

Siswa. Skripsi STKIP Subang.

Tidak diterbitkan. 